\title{
Análisis económico de las sanciones administrativas en el derecho de la competencia y el consumo**
}

\section{Economic analysis of administrative penalties in Competition and Consumer Law}

SUMARIO

Introducción. I. Fundamentos jurídicos y económicos del derecho de la competencia y del consumo en Colombia. II. El principio de legalidad en el derecho administrativo sancionador. III. Legislación de competencia y protección de consumidores, objetivo común pero... 1. Un vistazo al resultado de aplicar el modelo sancionatorio de competencia a infracciones sobre normas de protección al consumidor desde el enfoque jurídico tradicional. 2. Un vistazo al resultado de aplicar el modelo sancionatorio de competencia a infracciones sobre normas de protección al consumidor desde el Análisis Económico del Derecho. IV. Aplicación práctica a un caso en concreto -análisis de la Resolución 53403 de 2013 de la Superintendencia de Industria y Comercio-. Conclusiones.

* Abogado de la Universidad Externado de Colombia, especialista en Derecho Público de la misma Universidad. Curso en Law and Economics de la Universidad de Harvard en Cambridge, Mass. Magíster en Análisis Económico del Derecho y las Políticas Públicas de la Universidad de Salamanca. Ganador de la mención de honor del XXVI Concurso Nacional de Derecho Económico José Ignacio de Márquez, como autor del artículo "Tratamiento de la colusión en la contratación pública: una visión del caso colombiano". Investigador-docente del Departamento de Derecho Económico de la Universidad Externado de Colombia en temas de Análisis Económico del Derecho de la Competencia y la Regulación. Contacto: camilo.ossa@uexternado.edu.co

** Recibido el: 2 de noviembre de 2014, aprobado el: 12 de octubre de 2015.

Para citar el artículo: C. E. OsSA BocANEGRA, Análisis económico de las sanciones administrativas en el derecho de la competencia y el consumo, Derecho del Estado n. ${ }^{\circ}$ 35, Universidad Externado de Colombia, julio-diciembre de 2015, pp. 151-179. DOI: http://dx.doi. org/10.18601/01229893.n35.06

El presente artículo es el resultado de la investigación llevada a cabo en el periodo febrero-julio de 2014, dentro de la línea de investigación en Competencia y Consumo del Departamento de Derecho Económico de la Universidad Externado de Colombia, teniendo como proyecto, dentro de esta línea, el derecho continental. Financiado dentro del marco del convenio entre la Universidad Externado de Colombia y la Fundación por el Derecho Continental. 


\section{RESUMEN}

El artículo adelanta una revisión de un aspecto puntual relacionado con la posibilidad de que investigaciones originadas por infracciones al consumidor puedan ser sancionadas vía competencia, con el fin de aprovechar el mayor valor de la sanción, respecto de lo cual se hará una revisión de los aspectos jurídicos que ello implica, además de una propuesta, utilizando herramientas del Análisis Económico del Derecho, que nos puede llevar a convertir una sanción que se cree "reducida" en eficiente, siendo así óptima para el cumplimiento del fin propuesto en la misma ley. Son dos aspectos relacionados, primero, con la parte teórica que hay que tener en cuenta para este análisis, y segundo, con una aplicación práctica, que es en últimas la que origina la revisión de este tema donde consideramos existe un "problema".

\section{PALABRAS CLAVE}

Derecho de la competencia, derecho del consumo, regulación económica, responsabilidad civil, derecho administrativo sancionador.

\section{ABSTRACT}

The reader will find a review of a specific aspect related to the possibility that investigations arising from breaches of consumer can be sanctioned via competition, in order to take advantage of the higher value of the penalty, which it will review the legal aspects this, along with a proposal involves using tools of economic analysis of law, we can convert a lead to a sanction that believes "small" in efficient, being optimal for compliance with the proposed law in the same order. There are two specific aspects, first, related to the theoretical part that must be taken into account in this analysis, supported by a practical application, which is ultimately the originating reviewing this very spot where we believe there is a "problem".

\section{KEYWORDS}

Competition law, consumer law, economic regulation, civil liability, administrative law sanctions. 


\section{INTRODUCCIÓN}

En el presente artículo se pretende hacer un análisis del derecho de la competencia como herramienta sancionatoria respecto de conductas protegidas por las normas de consumo -incluido el régimen de protección de usuarios de comunicaciones-. Dicho análisis consta de la revisión tanto de los aspectos jurídicos como económicos que implica la realización de este tipo de prácticas por parte de la administración, entendiendo que, con independencia de los visos de ilegalidad que pueda contener, el objeto de las mismas es cumplir una función de prevención general frente a los demás competidores y frente al mismo sancionado; función que en principio podríamos sostener que no es posible realizar con el régimen sancionatorio establecido en las normas de consumo - por lo reducido del monto de las sanciones, frente al beneficio que puede reportar irrespetar la norma-. El mensaje que se quiere transmitir parecería ser más contundente con un régimen sancionatorio como el de competencia, dado el mayor valor de la sanción a imponer.

Sin embargo, veremos que esto no es del todo cierto y trataremos de proponer la Regla de Hand como una fórmula que, en la medida de lo posible, hace más eficiente la aplicación de las normas de consumo en relación con el fin perseguido. Para lograr esto, responderemos los siguientes interrogantes: ¿es posible que investigaciones originadas por infracciones al consumidor puedan ser sancionadas vía competencia para aprovechar el mayor valor de la sanción? ¿Cuál es el mejor modelo de sanción - responsabilidad-que logra disuadir al infractor sin necesidad de recurrir a herramientas sancionatorias de otro régimen normativo para buscar el cumplimiento efectivo de la ley?

$\mathrm{El}$ artículo se divide en tres partes: una primera relacionada con los fundamentos jurídicos y económicos que inspiran tanto el derecho de la competencia como el de consumo, revisando, además, uno de los pilares jurídicos fundamentales que soporta los procesos administrativos sancionatorios, como es el principio de legalidad (1); acto seguido, la propuesta de un modelo de responsabilidad que permita hacer más eficiente la aplicación de la sanción con el fin de cumplir con el objetivo de la ley (3); y, por último, una revisión práctica, basada en una crítica académica a un caso concreto resuelto por la autoridad de competencia en Colombia (4).

\section{FUNDAMENTOS JURÍDICOS Y ECONÓMICOS DEL DERECHO DE LA COMPETENCIA Y DEL CONSUMO EN COLOMBIA}

Colombia es un Estado social de derecho, que por un lado impone deberes y obligaciones y por el otro exige la adecuación del ordenamiento jurídico a los mandatos señalados en la Carta para el cabal desarrollo de lo allí preceptuado. 
La Constitución Política de Colombia, en el artículo 332 y siguientes, estipula lo relacionado con el régimen económico y de la hacienda pública, y fija los parámetros desde los cuales debe dirigirse la actividad económica como presupuesto fundamental del Estado social de derecho. De ahí que el artículo $334^{[1]}$ de la norma superior establezca que será el Estado, como encargado de la dirección general de la economía, el que intervenga, por mandato legal, en aquellos mercados que por sí mismos tienden a ser ineficientes, para grantizar la actividad económica y la libre competencia, tal y como lo señala el artículo 333 de la Carta.

Dicho en otras palabras, en relación con el derecho de la competencia y en especial con el ámbito de protección legal de dicha normativa, tanto el artículo 333 como el 334 habilitan al Estado, haciendo especial referencia a quién tiene asignada la función, para que haga dos tipos de intervención: i) la primera de ellas, cumpliendo un papel preventivo a través de una regulación ex ante o regulación económica; y también, ii) a través de lo que se llama regulación ex post, referida en este caso al derecho de la competencia por medio del cual el Estado sanciona o castiga un comportamiento desde el punto de vista jurídico.

Pero además hay que anotar que están dados los presupuestos para que el reproche también sea económico frente a todo comportamiento que atente de forma directa o indirecta contra el normal desarrollo del mercado y la economía en general, afectando no solo sus parámetros de eficiencia, sino tambien a los demás competidores y en consecuencia a los consumidores en general.

Sin embargo, como todo inicia desde la misma Constitución Política, no podemos dejar de lado el artículo 78 de la Carta, de donde sobrevienen dos efectos importantes en relación con el derecho del consumo -aquí estamos

$1 \quad$ El artículo 334 de la Constitución Política señala: "La dirección general de la economía estará a cargo del Estado. Este intervendrá, por mandato de la ley, en la explotación de los recursos naturales, en el uso del suelo, en la producción, distribución, utilización y consumo de los bienes, y en los servicios públicos y privados, para racionalizar la economía con el fin de conseguir en el plano nacional y territorial, en un marco de sostenibilidad fiscal, el mejoramiento de la calidad de vida de los habitantes, la distribución equitativa de las oportunidades y los beneficios del desarrollo y la preservación de un ambiente sano. Dicho marco de sostenibilidad fiscal deberá fungir como instrumento para alcanzar de manera progresiva los objetivos del Estado Social de Derecho. En cualquier caso el gasto público social será prioritario" (resaltado fuera de texto). Si se hace una interpretación del artículo 333, junto con el artículo 334 C.P., se advierte que el Estado, como fin esencial, de acuerdo con su modelo, ha fijado la garantía de la libertad económica y la libre competencia, para lo cual, en primera instancia, debe ser el mismo mercado el que fije las condiciones de funcionamiento, de acuerdo con lo que Adam Smith denominó en su momento la mano invisible; sin embargo, en los eventos en los cuales el mercado presente problemas asociados con la eficiencia por causa de un poder de mercado, el Estado, haciendo uso de la autorización dada en el artículo 334, intervendrá para el restablecimiento del mismo. 
hablando de los consumidores en general, sin circunscribirnos exclusivamente al Estatuto del Consumidor, por lo que también están comprendidos los derechos de los usuarios de comunicaciones relacionados en la Ley 1341 de 2009-: el primer efecto que hay que tener en cuenta es que nos encontramos en el capítulo III de la Constitución, el cual se refiere a los derechos colectivos y del medio ambiente -en términos doctrinales, hablamos de derechos de tercera generación ${ }^{2}-$.

El segundo efecto está dado por el ámbito de protección que encierra tales derechos, con lo cual hay que anotar que, al pertenecer a los derechos de tercera generación -constituyendo como tales derechos e intereses colectivos-, los mecanismos desarrollados por la ley para garantizar su protección y promoción son varios, tanto generales como particulares, donde cada uno tiene una misión propia en tanto protección de derechos e intereses precisos -bien se trate de una protección específica o bien de una protección general, por el solo hecho de ser un derecho que protege a un consumidor (in)determinado-.

Aun cuando vemos que tanto el derecho de la competencia como el derecho del consumo tienen fundamentos constitucionales diversos -bajo el entendido de que son diferentes categorías normativas las que lo justifican-, debemos ser consistentes en decir que ambas categorías normativas (consumo y competencia) integran lo que conocemos como la Constitución Económica. Así, bajo ese entendido, hay que señalar que cuando hablamos de Constitución Económica inmediatamente debemos trasladarnos al modelo económico fijado en la Constitución, como aquel que consiste en "el conjunto de principios, criterios, valores y reglas fundamentales que presiden la vida económico-social de un país, según un orden que se encuentra reconocido en la Constitución”’3.

Para Uprimny y Rodríguez es posible señalar que la nuestra es una Constitución valorativa "porque consagra principios y valores específicos", pero

2 En este punto es fundamental señalar cuanto bien dice PÉREZ LUÑO: "A las tres generaciones de Estados de derecho corresponden, por tanto, tres generaciones de derechos fundamentales [...] El Estado constitucional, en cuanto Estado de derecho de la tercera generación, delimitará el medio espacial y temporal de paulatino reconocimiento de los derechos de la tercera generación. La estrategia reivindicativa de los derechos humanos se presenta hoy con rasgos inequívocamente novedosos al polarizarse en torno a temas tales como el derecho a la paz, los derechos de los consumidores, el derecho a la calidad de vida, o la libertad informática. En base a ello, se abre paso, con intensidad creciente, la convicción de que nos hallamos ante una tercera generación de derechos humanos complementadora de las fases anteriores, referidas a las libertades de signo individual y a los derechos económicos, sociales y culturales. Los derechos y libertades de la tercera generación se constituirán, por tanto, en garantía frente a los riesgos y amenazas para las libertades producidos por los usos abusivos de las Nuevas Tecnologías": A-E. PÉREZ LuÑo. La tercera generación de derechos humanos. Navarra, Thomson Aranzadi, 2006, p. 75.

3 G. Ariño Ortiz. Principios de Derecho Público Económico. Bogotá, Universidad Externado de Colombia, 2003, p. 175. 
no establece un modelo económico "preciso" . No obstante, podemos afirmar que la Constitución señala los fines que debe cumplir el Estado, económicamente hablando, en el ejercicio de sus funciones -pudiendo encasillar aquí lo que comúnmente conocemos como intervención pública de la economía-. Para Stiglitz, el Estado interviene en la economía para corregir los fallos del mercado - problemas de eficiencia- y de redistribución social de las rentas ${ }^{5}$.

Sin embargo, dicha intervención pública dependerá del modelo económico adoptado por cada país en el que se quiera hacer este análisis; así, nuestro modelo económico está atado a nuestro Estado como social de derecho, debiendo este asumir todas las acciones necesarias con el fin de cumplir su obligación de asistencia social, garantía de derechos y libertades, y también de efectividad en la provisión de las condiciones mínimas vitales para la subsistencia digna de sus ciudadanos.

De otra parte, tener el modelo propio de un Estado social de derecho lleva implícito el principio de legalidad, con un respeto y acatamiento de la Constitución y la ley en todas sus formas de manifestación en pro del bien común y del cumplimiento de los fines del Estado. Como bien lo señala Correa: "el significado del Estado Social de Derecho no puede trazarse, pues, con negación de la libertad económica, de la libre competencia, del derecho a la propiedad y la protección de los trabajadores, la seguridad social, la salud, el medio ambiente, la dignidad humana, el bienestar colectivo, no puede sustentarse desde la negación de la libertad de empresa en el marco de la economía de mercado". A lo cual yo agregaría la protección de los derechos e intereses de los consumidores como concepto que ayuda a determinar en sí mismo el alcance del modelo de Estado que rige desde nuestra Constitución.

En ese mismo sentido, siendo fundamental para lo inicialmente expuesto en este artículo, continúa Correa señalando que "el sistema económico constitucional concebido en [...] Colombia es efectivamente el de la economía de mercado con carácter social, comúnmente nominado como 'economía social de mercado', como expresión que adscribe al sistema económico de la Constitución lo libre económico con lo social, a la vez que la aplicación también en el ámbito económico del principio pro libertate como supuesto que integra la noción de Estado Social de Derecho"”.

4 R. UPRIMNY YePES y C.A. RodRíGUEZ G. Constitución y modelo económico en Colombia: hacia una discusión productiva entre economía y derecho. Centro de Estudios de Derecho, Justicia y Sociedad, Bogotá, 2005, p. 25.

5 J. E. Stiglitz. La economía del sector público. Barcelona, Bosch, 2000, p. 91.

6 M. Correa Henao. Libertad de empresa en el Estado Social de Derecho. Bogotá, Universidad Externado de Colombia, 2008, p. 134.

7 Ibíd., p. 135. 
Teniendo lo anterior como presupuesto, es necesario remitirnos al concepto, para así entender en qué consiste la economía social de mercado, teniendo como tal, en palabras de Resico, aquella economía que

... se basa en la organización de los mercados como mejor sistema de asignación de recursos y trata de corregir y proveer las condiciones institucionales, éticas y sociales para su operatoria eficiente y equitativa. En casos específicos, requiere compensar o corregir posibles excesos o desbalances que puede presentar el sistema económico moderno basado en mercados libres, caracterizado por una minuciosa y extensa división del trabajo y que, en determinados sectores y bajo ciertas circunstancias, puede alejarse de una competencia funcional. Descarta como sistema de organización la economía planificada centralmente ${ }^{8}$.

De lo cual, centrándonos en el ordenamiento jurídico colombiano, dicho sistema económico representa la "interacción fluida" entre la economía de mercado y el Estado social de derecho, "que además de los derechos y libertades que consagra también impone y habilita al Estado para encauzar la economía hacia la consecución del interés general que es social, cultural, ambiental y también económico, y por lo que se dispone en consecuecia, la dirección de la economía por parte del Estado desde muchas perspectivas (la ordenadora, la reguladora, la gestora)" .

Sin embargo, y tambien sin importar cuál sea el interés o derecho que busca protegerse, bien sea de un consumidor o usuario o de los competidores en cuanto tales, hablando como sistema económico, el fin último, por parte de aquel a quien corresponde diseñar y ejecutar la política pública que garantice lo preceptuado por la Constitución en relación con los derechos aquí discutidos-competencia y consumo-, es impedir cualquier abuso de posición dominante, porque con ello mantiene las condiciones del mercado -por lo menos intenta acercarse a una competencia perfecta- y al unísono protege a los consumidores del abuso que puede generar la posición dominante.

La claridad que debe tenerse al respecto, porque así lo ha determinado el mismo ordenamiento jurídico, es que cada uno de los derechos tiene su propio ámbito de protección, circunscrito tanto a los derechos de los consumidores y usuarios como al derecho de la competencia, donde el primero (consumo) es totalmente diferente -por lo menos en tratándose de legislaciones aplicablesdel segundo (competencia), como categorías independientes la una de la otra.

8 M. RESICO. Introducción a la Economía Social de Mercado. Rio de Janeiro, Konrad Adenauer Stiftung, 2011, p. 115.

9 M. Correa Henao. Libertad de empresa en el Estado Social de Derecho. Bogotá, Universidad Externado de Colombia, 2008, p. 138. 
Es aquí donde podemos decir que, en la búsqueda de dar amparo a situaciones en las cuales una acción u omisión puede transgredir los derechos asignados a los ciudadanos, se ha implementado, por parte del Estado, una legislación que los ampare; sin embargo, el punto de quiebre está en determinar cuál es el régimen sancionatorio aplicable, competencia o consumo -partiendo del supuesto de que se ha transgredido el bien jurídico protegido con la norma y en consecuencia tal conducta requiere reproche normativo (principio de legalidad)-. Aspecto que iremos desarrollando en el transcurso del artículo.

\section{EL PRINCIPIO DE LEGALIDAD EN EL DERECHO ADMINISTRATIVO}

\section{SANCIONADOR}

En este punto en particular, debemos tener como premisa que el derecho administrativo sancionador -al igual que cualquier otro que afecta derechos, solo por citar un ejemplo- trabaja, en estricto sentido, bajo la óptica legal, al decir que "nos referimos a la necesaria condición jurídica del fin administrativo, previsto en normas con rango de ley. Toda competencia se encuentra sometida a la extensión de la potestad que la origina, y a su vez al fin que caracteriza dicha potestad. La búsqueda de tal fin debe realizarse en el título legal que contempla la atribución, donde suele hallarse bajo el término de 'orientaciones', 'objetivos' o, más expresivamente, 'finalidades"' 10 .

Aunado a lo anterior y con el fin de ir centrándonos en el punto específico que aquí nos interesa tratar en relación con el derecho administrativo sancionador, es necesario analizar el principio de legalidad desde dos perspectivas diferentes en su concepción, pero ligadas en cuanto a la aplicación de la norma jurídica de la que se vale la administración para sancionar o reprochar determinado comportamiento ${ }^{11}$. Así, hay que tener en cuenta la concepción jurídico-administrativa que acompaña dicha aplicación legal: i) por un lado

10 D. SARMiento RAmírez-ESCUDERo. El principio de proporcionalidad en el Derecho Administrativo. Un análisis jurídico desde el derecho español. Bogotá, Universidad Externado de Colombia, 2007, p. 144.

11 Sobre el principio de legalidad en el derecho administrativo sancionador, el Tribunal Constitucional de España ha expuesto: "Dicho principio comprende una doble garantía: la primera, de orden material y alcance absoluto, tanto referida al ámbito estrictamente penal como al de las sanciones administrativas, refleja la especial trascendencia del principio de seguridad jurídica en dichos campos limitativos y supone la imperiosa necesidad de predeterminación normativa de las conductas infractoras y de las sanciones correspondientes, es decir, la existencia de preceptos jurídicos (lex praevia) que permitan predecir con suficiente grado de certeza (lex certa) aquellas conductas y se sepa a qué atenerse en cuanto a la aneja responsabilidad y a la eventual sanción; la segunda, de carácter formal, relativa a la exigencia y existencia de una norma de adecuado rango y que este Tribunal ha identificado como ley en sentido formal": Sentencia del Tribunal Constitucional de España n. ${ }^{\circ} 61$ de 29 de marzo de 1990 (resaltado fuera de texto). 
desde el punto de vista de la función administrativa, y, ii) por el otro en cuanto a la norma sustancial y procedimental que habilita dicha sanción por parte de la administración.

i) El primero de ellos es en relación con el funcionario público, para el cual se entiende que solamente puede realizar o ejecutar -dependiendo del tipo de actividad que le sea propia- aquello que se encuentra expresamente asignado a su función; en otras palabras, solo puede hacer aquello que le está expresamente permitido ${ }^{12}$, diferente al particular quien puede realizar todo aquello que no se encuentre prohibido, dando cabida al principio de la autonomía de la voluntad "que rige en derecho privado, afirmando que todo lo que no está prohibido está permitido para los ciudadanos"13.

ii) De aquí un segundo enfoque, que realmente se desprende del primero por su indivisibilidad en la aplicación, y es el principio de legalidad referido exclusivamente a la norma sustantiva y procedimental, donde, al momento de sancionar o reprochar una conducta por parte de la administración, dicha conducta debe estar previamente configurada en la ley como una infracción, y la sanción a imponer debe estar prevista como tal por la legislación aplicable. En este mismo sentido, la doctrina señala que "el sujeto pasivo de la acción punitiva puede vocear su derecho a conocer anticipadamente cuáles son las consecuencias que le acarrearía la comisión de un acto o de una conducta antijurídica en el ambito administrativo, ya que lo que más se subraya es que al paticular no se le pueden crear normas sustantivas posteriores a la infracción y tampoco juzgársele con procedimientos creados para el caso específico, pues las reglas legales deben ser preexistentes al acto que se le imputa, según mandato supra legal"14.

Decimos que estos dos enfoques se encuentran íntimamente ligados en tanto y en cuanto el funcionario en ejercicio de su función solo puede hacer aque-

12 Sobre este punto en particular, resalta SANTAMARÍA PASTOR: "En primer lugar, la norma puede erigirse en el fundamento previo y necesario de una determinada acción, la cual, por lo tanto, solo podrá realizarse válidamente en la medida en que la norma habilite al sujeto para ello; en ausencia de dicha habilitación normativa, pues, la acción debe considerarse como prohibida; esta forma de sujeción que suele denominarse como vinculación positiva, se expresa con la máxima latina quae non sunt permissae prohibita intelliguntur (lo que no está permitido, se considera prohibido) [...] [T] odas las acciones de la Administración deben apoyarse y justificarse en una ley previa que le habilite para realizarlas": J. A. SANTAMARIA PASTOR. Principios de Derecho Administrativo. Madrid, Centro de Estudios Ramon Areces, 1994, p. 52.

13 J. O. Santofimio Gamboa. Tratado de Derecho Administrativo, vol. II, Acto Administrativo. Bogotá, Universidad Externado de Colombia, 2003, p. 42.

14 J. Ossa Arbelaez. Derecho Administrativo Sancionador. Hacia una teoría general y una aproximación para su autonomía. Bogotá, Legis, 2000, 241. 
llo para lo cual se encuentra expresamente autorizado, es decir, debe ser de su resorte sancionar la infracción, pero además por conductas previamente señaladas en la ley como típicas de un comportamiento reprochable por el ordenamiento jurídico. Son estos los elementos que en definitiva estructuran el principio de legalidad: i) la reserva legal -dado que es del resorte exclusivo de quien hace las leyes-; ii) la tipificación, por cuanto la infracción debe ser típica, es decir, estar descrita en la ley como tal-; iii) el non bis in idem -principio traído del derecho penal ${ }^{15}$ que prohíbe sancionar dos veces la misma conducta-, y, iv) la irretroactividad de la norma sancionadora desfavorable-que también es un principio propio del derecho penal consistente en la proscripción de sancionar con una norma posterior al hecho cuando la misma reporta una desfavorabilidad en relación con la norma vigente pertinente y aplicable al caso concreto- ${ }^{16}$.

En suma, tenemos que, en lo relacionado con el procedimiento administrativo sancionador, tanto las infracciones como las sanciones -yo agregaría, además, la función- deben estar definidas por la ley al momento en que "se produzca la omisión o sanción reputada constitutiva de infracción administrativa" ${ }^{17}$. De esta manera, es claro que la cláusula de Estado social de derecho que acompaña nuestro modelo de Estado obliga a que las actuaciones encaminadas a cumplir con su fin esencial estén precedidas por el acatamiento irrestricto del principio de legalidad, fórmula que lleva implícito el deber de adelantar las investigaciones y procedimientos de acuerdo a la materia sobre la cual se ha producido la infracción.

En otras palabras y para centrar el asunto, se tiene que, si se ha cometido una infracción de acuerdo al derecho del consumo, el procedimiento y la sanción aplicable deben ser los previstos para este tipo de conductas, contenidas bien sea en el Estatuto del Consumidor o en la Ley 1341 de 2009 cuando se trata de derechos de usuarios de comunicaciones, solo por citar estos dos ejemplos;

15 La Corte Constitucional ha ratificado lo que ya ha entendido la doctrina en cuanto a la aplicación de los principios del derecho penal al derecho administrativo sancionador. En palabras de la Corte: "Si bien la doctrina sobre la materia ha reconocido que la aplicación de los principios y reglas del derecho penal delictivo al derecho administrativo sancionador, y entre ellos, al derecho disciplinario, tiene como fundamento la homogeneización o unidad punitiva exigible en tratándose del ejercicio del ius puniendi; de igual manera se ha admitido la existencia de una singularidad en cada uno de sus procedimientos (penal, correccional, contravencional o disciplinario), en respuesta a la naturaleza de los ilícitos y de sus sanciones, así como a la mayor intervención de las sanciones administrativas sobre las penales en el ordenamiento jurídico": Corte Constitucional. Sentencia C-818 de 9 de agosto de 2005, M.P.: Rodrigo Escobar Gil, exp. D-5521.

16 A. Nieto. Derecho Administrativo Sancionador. Madrid, Tecnos, 1994, p. 216.

17 L. Parejo Alfonso, A. Jiménez-Blanco y L. Ortega Álvarez. Manual de Derecho Administrativo. Barcelona, Ariel, 1990, p. 248. 
y no utilizar una sanción propia del derecho de la competencia para así imponer condenas mucho más altas, lo que en definitiva constituye un atropello no solo respecto del investigado sino del ordenamiento jurídico en general.

Pongamos las cosas en orden; esta práctica de entrada lleva consigo varias irregularidades, las cuales podemos enumerar como sigue:

i) En primer lugar, es un incumplimiento evidente del principio de legalidad arriba expuesto por cuanto lo que hace en este caso el encargado por ley de llevar a cabo este procedimiento administrativo sancionador es suplantar al legislador. Recordemos que líneas atrás dijimos que en materia administrativa sancionadora tanto las infracciones como las posteriores sanciones que haya lugar a imponer por el incumplimiento de la norma deben estar definidas en la ley.

Mirémoslo así: si yo como funcionario encargado de imponer sanciones ante el incumplimiento recojo las infracciones de un estatuto normativo, por decir algo de consumo, pero al mismo tiempo tomo la sanción propia de otro estatuto normativo, como sería el caso del de la competencia, estoy creando una nueva ley -lo que en derecho penal se conoce como lex tertia-, lo cual es abiertamente ilegal, así al momento de realizar esta conducta la misma se cubra bajo el ropaje de un mismo procedimiento. Aquí lo que hace la administración es tomar la infracción, por citar un ejemplo, del derecho de la competencia, así ella sea propia del derecho del consumo, adelantar toda la investigación y al final imponer la sanción como si se tratara de un problema de competencia, cuando lo que busca la administración es valerse del régimen sancionatorio de este, por su elevado monto sancionatorio en comparación con los niveles punitivos propios del derecho del consumo.

ii) Por otro lado, podemos contar una segunda irregularidad, que en definitiva es consecuencia directa de la primera: hablamos de la violación al debido proceso, lo que a su vez se traduce en un desconocimiento del derecho de defensa, en tanto y en cuanto es muy diferente el sentido que se le da a una defensa encaminada a desvirtuar un acto, acuerdo, abuso de posición dominante o una competencia desleal, al sentido que se le puede dar a la defensa que intenta desvirtuar una vulneración a los derechos de los consumidores.

iii) La inseguridad jurídica creada para el receptor de la norma, quien en definitiva no sabrá con un suficiente grado de certeza a qué sanción se puede ver expuesto si acomete $x$ o y infracción, con el riesgo implícito además de incurrir en un iv) non bis in idem, bajo una sábana diferente pero sobre la misma cama, en el entendido de que una normativa protege la libre competencia económica y el otro el derecho de los consumidores. Y, por último, v) se genera un incentivo perverso que va en contravía de los mismos consumidores en tanto, al existir inseguridad jurídica con relación a la norma 
aplicable al caso concreto, el receptor de la norma lo que hace es cargar, al bien o servicio ofrecido, un porcentaje del valor de la sanción promedio a la que se puede ver expuesto, el cual en últimas lo debe asumir el consumidor. En tales casos, hace el productor el siguiente análisis:

Los productores solo pueden reducir el riesgo de la mala calidad del producto a través de la elección de un determinado nivel de cuidado (lo cual le cuesta dinero al productor). Entonces $X$ representa los desembolsos en cuidado (o el valor monetario del esfuerzo) y $P(X)$ representa la probabilidad de que un accidente cause un perjuicio $H$, donde $P$ disminuye si $X$ aumenta. Asumamos que el objetivo social es minimizar el total de los costos proyectados, $X+P(X) H$, y que $X^{*}$ denota el $X$ óptimo ${ }^{18}$.

En la fórmula anterior, para explicar nuestra teoría vamos a hacer una variación, donde $H$ hace alusión no al valor del daño sino al valor de la sanción. Así las cosas, si la sanción $H$ es muy alta, $X$ sube ( $X$ como el valor en prevención); si, por el contrario, $H$ baja, el valor en $X$ baja, hasta el punto en que $H$ promedia y por ende el valor en $X$ se mantiene promedio. Por lo tanto, $X$, como ese valor adicional a la producción -hablamos de aumentar el nivel de cuidado-, hace que los costos de producción aumenten, provocando una subida en el valor del bien o servicio ofrecido.

\section{LEGISLACIÓN DE COMPETENCIA Y PROTECCIÓN DE CONSUMIDORES, OBJETIVO COMÚN PERO...}

Si bien es cierto que tanto el derecho de la competencia como el derecho de consumo tienen objetivos comunes, también es cierto que cada uno de ellos opera de manera independiente tanto en su concepción como en su aplicación, o mejor, tanto en el ser como en el deber ser.

En relación con el objetivo común hay que decir que a la competencia y al consumo los une la eficiencia económica y el bienestar social en los mercados de consumo, "con el punto de mira en la política redistributiva, o desde una visión paternalista sobre cómo deberían entenderse los derechos legales y económicos de la población de consumidores" ${ }^{19}$.

18 S. SHAVELL. Responsabilidad extracontractual por accidentes en el análisis económico del derecho. En: C. Bernal Pulido y J. FABra Zamora. La Filosofía de la Responsabilidad Civil. Estudios sobre los fundamentos filosófico-jurídicos de la responsabilidad civil extracontractual. Bogotá, Universidad Externado de Colombia, p. 456.

19 F. Gómez POMAR. La relación entre normativa sobre protección de consumidores y normativa sobre defensa de la competencia. Barcelona, Working Paper n. ${ }^{\circ} 113,2003$, pp. 3-4. 
Así, podemos entender que el objetivo de la normatividad de competencia es preservar y mejorar la estructura competitiva de los mercados de bienes y servicios.

Como se puede apreciar con la más sencilla teoría económica, los grandes beneficiados por las estructuras competitivas de los mercados son, precisamente, los consumidores de los bienes y servicios. La competencia perfecta asegura que todos los consumidores que valoran un determinado bien o servicio por encima de lo que costaría a la sociedad producir el bien o prestar el servicio, lo obtendrán por un precio que refleje su coste social exacto. Así, se consiguen simultáneamente la eficiencia distributiva (allocative efficiency) y la eficiencia productiva. Además, el excedente que se genera por la producción y el suministro de los bienes en un mercado competitivo se atribuye completamente a los consumidores, de manera que su situación no puede mejorarse mediante políticas gubernamentales o reglas legales ${ }^{20}$.

Dicho esto, podemos afirmar que el derecho de la competencia es una rama del derecho que se encarga de la promoción de la libertad económica, la libertad de empresa, el mantenimiento de la eficiencia en los mercados y la protección de los consumidores, también entendida como "el conjunto de normas jurídicas que pretenden regular el poder actual o potencial de las empresas sobre determinado mercado en aras del interés público" ${ }^{21}$. Con lo cual sostenemos dos cosas: i) la primera, en relación con la eficiencia de los mercados ${ }^{22}$, donde, en últimas, el beneficiario directo de dicha eficiencia será

20 Ibíd., p. 4.

21 A. MiRANDA LONDOÑo. Origen y evolución del derecho de la competencia en Colombia. La Ley 155 de 1959 y su Legado. Revista de Derecho de la Competencia, Bogotá, diciembre de $2011,69$.

22 Este constituye un punto importante para lo que pretendemos develar en relación con el objetivo común del derecho de la competencia y el del consumo, dado que, en últimas, de lo que hablamos cuando uno u otro derecho busca proteger a través de sus normas, es corregir las fallas de mercado, que es un común denominador de ambos sistemas normativos, siendo que las fallas del mercado son "una situación en la que no se encuentra el primer óptimo a partir del funcionamiento del mercado; en otras palabras los requisitos del modelo de libre competencia no se cumplen y por tanto la economía no es capaz de alcanzar situaciones de eficiencia asignativa, productiva y paretiana. En esta circunstancia, el mercado no asigna eficientemente la producción o la asignación de bienes para los consumidores, al no generar las señales necesarias a los agentes a través de los precios; implica que no puede garantizar que se produzcan las debidas cantidades, existiendo una diferencia entre el costo privado y el costo social de una actividad": L. E. AMADOR CABRA. Regulación, fallas del mercado y eficiencia económica en el sector del saneamiento básico. En: C. Blanco Barón, A. Guerra Barón, M. A. Pinzón Camargo, A. Palacios Lleras y L. E. Amador CABra. Coleción Enrique Low Murtra Derecho Económico VII. Bogotá, Universidad Externado de Colombia, 2010, p. 305. 
el consumidor como destinatario del bien o servicio ofrecido en el mercado; ii) la segunda, teniendo como fin último del derecho de la competencia la protección de los consumidores, bajo la máxima según la cual, cuando el derecho de la competencia busca atajar el poder de mercado y las prácticas colusorias de manera directa, beneficia a los consumidores, quienes son los encargados de aprovechar los réditos económicos de un mercado competitivo.

Ahora bien, dicho lo anterior tenemos que ambos regímenes normativos basan su intervención en las fallas del mercado; sin embargo, y en esto debemos ser precisos, no es eficiente usar un régimen para corregir problemas que no le son propios -no podemos usar el derecho del consumo para corregir problemas propios del derecho de la competencia o viceversa-, y esto por varias razones. Veamos.

En primer lugar, de utilizar un sistema para corregir los problemas del otro se generarán distorsiones en cuanto al régimen aplicable a cada una de las conductas que puede acometer el destinatario de la norma en concreto. Recordemos que el derecho del consumo es utlizado para corregir problemas de asimetría de información, mientras que el derecho de la competencia se usa para los problemas propios del poder de mercado, y en concordancia con esto es que pueden surgir obligaciones, en uno u otro sentido, para los diferentes agentes del mercado.

En segundo lugar, "porque a los legisladores, a las agencias reguladoras o a los tribunales les resulta más que complicado recopilar y elaborar toda la información necesaria para determinar de forma razonable el nivel óptimo de todos los términos contractuales relevantes", o la finalidad perseguida con la conducta desplegada.

En tercer lugar, "porque la imposición legal de niveles de calidad y términos contractuales para las negociaciones con consumidores en las que existe un vendedor monopolista puede inducir no a un mejor servicio para todos los tipos de consumidores, sino simplemente a un aumento en los precios que excluiría del acceso al producto o al servicio a aquellos grupos con una menor predisposición a pagar por él" 23 .

En este punto debemos aclarar que, aun cuando los tres supuestos mencionados hacen referencia a ineficiencias asociadas a los mercados desde una visión ex ante (regulación), "la misma tiene como objetivo primordial corregir las fallas del mercado en la búsqueda del mismo balance que se obtendría en mercados competitivos" 24 ; "mientras que la regulación ex post busca conmi-

23 GómEZ POMAR. La relación entre normativa sobre protección de consumidores y normativa sobre defensa de la competencia, cit., p. 11.

24 AMADOR CABRA. Regulación, fallas del mercado y eficiencia económica en el sector del saneamiento básico"., cit., p. 310. 
nar a que los agentes del mercado se comporten de forma leal y competitiva en el avance de sus actividades económicas para no perturbar las condiciones preestablecidas en los mercados" ${ }^{25}$; por lo cual debemos advertir que tanto el poder de mercado como la asimetría de información son supuestos que son atacados bien sea de manera ex ante o ex post, pero la existencia de uno implica la debida observancia por parte del otro.

Es por esto que, aun cuando existen objetivos comunes en el ámbito de protección de cada uno de estos derechos, toda norma destinada a combatir aquellas conductas que atenten contra los derechos de los consumidores y la libre competencia tiene que ir encaminada a atacar uno de varios problemas, los cuales tienen su razón de ser en las fallas del mercado: y es precisamente esto lo que hace que, aun cuando compartan objetivos comunes, los mismos afronten situaciones económicas diferentes.

Así, las normas de competencia deben centrarse en corregir los problemas propios del poder de mercado, mientras que el derecho del consumo debe encaminarse a corregir los problemas propios de la asimetría de información, dado que si los usuarios o consumidores tuvieran una información completa respecto de la calidad del producto, las características del bien o servicio ofrecido, la exactitud en la información que reciben, así como de sus derechos y obligaciones, etc., se generarían incentivos suficientes para que el productor o proveedor del bien o servicio aumentara los estandares de calidad. Así, "si la empresa ofreciese un nivel de calidad -por ejemplo, en los derechos y obligaciones en caso de incumplimiento contractual- menor que el preferido por los consumidores, ese hecho comportaría que el valor del incremento en la calidad para los consumidores superara el coste necesario para que la empresa proveyera esa calidad adicional deseada por los consumidores" 26 .

Adicional a lo anterior y aún bajo el entendido de que cada uno de estos derechos tiene sus objetivos comunes, sus males no solo deben atacarse desde perspectivas diferentes, como ya lo mencionamos -el poder de mercado a través del derecho de la competencia y la asimetría de información a través del derecho del consumo-, sino que, de forma adicional, el ordenamiento jurídico colombiano ha previso un sistema normativo para cada uno de ellos, de forma independiente y con características especiales que los diferencian, incluso en su aplicación; donde su trascendencia económica puede implicar, en ocasiones, afectaciones "tan graves como las penas del código penal, por-

25 C. Ossa Bocanegra. Fundamentos de la aplicación pública del derecho de la competencia en Colombia. Revista Facultad de Derecho y Ciencias Políticas. Universidad Pontificia Bolivariana, Medellín, 2014, vol. 44, n. ${ }^{\circ} 120$, p. 210.

26 GómEz POMAR. La relación entre normativa sobre protección de consumidores y normativa sobre defensa de la competencia, cit., p. 8. 
que aunque la Constitución prohíbe las sanciones consistentes en privación de la libertad, sus consecuencias pueden afectar al desarrollo de una actividad empresarial de forma considerable" 27 .

\section{Un vistazo al resultado de aplicar el modelo sancionatorio de competencia a infracciones sobre normas de protección al consumidor desde el enfoque jurídico tradicional}

Desde un enfoque jurídico tradicional, el resultado que arroja la aplicación de un modelo clásico de responsabilidad civil a conductas que, por su concepción, son típicas de un marco normativo como el derecho del consumo genera efectos diferentes de acuerdo tanto con el modelo de responsabilidad que se predique como con el régimen sancionatorio aplicable a cada una de las conductas que se considera dañosa, no solo desde el punto de vista del consumidor, sino de la competencia.

En primer lugar tenemos que desde un enfoque tradicional de la responsabilidad civil, el daño debe resarcirse en una proporción equivalente a la magnitud del daño causado, esto es, "la reparación del daño debe dejar a la persona indemne, en una situación similar a la que se encontraba antes que el hecho dañoso ocurriera" 28 ; o, desde otra perspectiva, se puede decir que "tendrá derecho el acreedor a que se le repare el daño en una cantidad equivalente o superior a los costos del cumplimiento; así el derecho internaliza todos los costos de incumplir a tráves de la responsabilidad civil" ${ }^{29}$, lo cual en muchos casos puede llevar consigo un efecto negativo en el sentido de incentivar al "deudor" a incumplir, teniendo en cuenta que el cumplimiento en algunos casos resulta más oneroso que el incumplimiento.

De aquí surge una conclusión importante a tener en cuenta, y es que, en segundo lugar, lo que debería buscar la administración al momento de sancionar no es la imposición de multas y sanciones, sino, por el contrario, el cumplimiento eficiente por parte de quien tiene la obligación de cumplir con lo pactado -en caso de los contratos- o de realizar su actividad dentro de los cánones de la lealtad comercial y la libre competencia económica-cuando

27 R. Rivero Ortega. Derecho Administrativo Económico. Madrid, Marcial Pons, 2009, p. 166.

28 J.C. HENAO. El daño. Análisis comparativo de la responsabilidad extracontractual del Estado en derecho colombiano y francés. Bogotá, Universidad Externado de Colombia, 1998, p. 45 .

29 R. BARCia Lehmann. Los efectos de las obligaciones desde la perspectiva del Análisis Económico del Derecho. Cuadernos de Análisis Jurídicos. Colección de Derecho Privado I. Temas de Responsabilidad Civil. Universidad Diego Portales, Escuela de Derecho, Santiago de Chile, 2004, p. 142. 
hablamos de los objetivos antitrust-. Así, desde este enfoque, el análisis económico de la responsabilidad civil "exigirá no solo el cumplimiento, sino que el mismo sea efiiente, en cuyo caso la responsabilidad deberá ser igual al beneficio que representa para el acreedor el cumplimiento" ${ }^{30}$. De esta manera habrá incentivos para el cumplimiento, teniendo en cuenta que cuando el empresario hace el análisis costo-beneficio siempre resulta mejor cumplir que incumplir.

Trasladando este presupuesto al asunto en concreto, vemos que cuando la administración aplica a una determinada conducta un régimen sancionatorio más alto y que no le corresponde en verdad, pero que se puede adecuar, su intención es cumplir una función de prevención general positiva con el fin de disuadir a todos los agentes participantes en el mercado -receptores de la norma- de ejecutar una conducta prohibida por el ordenamiento jurídico, lo cual, desde nuestro punto de vista, no solo es irregular sino que deja abierta la posibilidad a la futura declaración de nulidad por parte de la autoridad contencioso administrativa.

Por ejemplo, si tomamos una infracción al régimen de protección de usuarios de comunicaciones como lo es la portabilidad númerica, prevista en la Ley 1245 de 2008 y regulada por la Resolución CRC 3066 de 2011, artículo 9. , tenemos que la sanción máxima imponible de acuerdo a la Ley 1341 de 2009 es de dos mil salarios mínimos legales mensuales vigentes; pero si adecuamos dicha conducta a una vulneración del numeral 6 del artículo 50 del Decreto 2153 de 1992, tenemos que se puede sancionar hasta por cien mil salarios mínimos legales mensuales vigentes o el " $150 \%$ de la utilidad derivada de la conducta por parte del infractor". La diferencia es gigantesca, y sin embargo, aun cuando determinada conducta fácilmente puede encajar en cualquiera de los regímenes jurídicos, en estos casos existe previamente una regulación que les da el carácter de especial aplicación a las normas de consumo.

Es claro, pues, que cuando hablamos de libre competencia y derecho del consumo - por no decir que del derecho sancionador en general, que también lo cumple- tienen una función de prevención general positiva, y de hecho debe la administración buscar que así sea, pero existen otros mecanismos, como lo veremos en el siguiente epígrafe, más idóneos que el señalado en el ejemplo, que más bien se parece a lo que en derecho penal se llama lex tertia, además de encontrarnos ante una clara suplantación de la función legislativa. 


\section{Un vistazo al resultado de aplicar el modelo sancionatorio correspondiente a infracciones sobre normas de protección al consumidor desde el Análisis Económico del Derecho}

De acuerdo con lo que veníamos señalando líneas atrás, el enfoque puede cambiar de acuerdo con lo que se pretenda al momento de imponer una determinada sanción. Como ya lo mencionamos, en el derecho administrativo sancionador en general, y en lo que tiene que ver con el derecho de la competencia y el consumo en particular, la imposición de la sanción cumple además una función de prevención general positiva; sin embargo, la mejor solución es la que proponemos a continuación, y no la que describimos en el epígrafe anterior -dado que resulta ineficiente, tanto por la violación del principio de legalidad como por el aumento del coste social que plantea la incertidumbre jurídica-; es decir, la mejor solución no es aplicar un modelo sancionatorio que no le corresponde para poder sancionar más, sino todo lo contrario, aplicar el que corresponde, acompañado de un análisis económico de la responsabilidad atribuida al empresario con el fin de tener sanciones eficientes en beneficio tanto de los competidores como de los consumidores.

La idea aquí esbozada es llamar la atención en el sentido de afirmar que sí es posible cumplir una función de prevención general positiva en materia de consumo, aplicando el régimen sancionatorio correspondiente y no adecuando comportamientos a otro tipo de figuras que escapan al ámbito de protección del derecho del consumo.

Así las cosas, lo primero que debemos señalar es que todo arranca con el modelo de responsabilidad que se adopte, en el sentido de que no es lo mismo predicar una responsabilidad objetiva que una subjetiva en materia de consumo. Veamos.

\section{Responsabilidad objetiva}

En materia de consumidores, adoptar un sistema de responsabilidad objetiva puede generar incentivos perversos y por el contrario tiende a eliminar los incentivos para prevenir ${ }^{31}$; veámoslo de la siguiente forma: i) pagar indemnizaciones y sanciones es costoso, pero ii) prevenir accidentes o invertir en calidad también lo es, de lo cual podemos distinguir dos tipos de empresarios, el empresario "malo" (i) y el "bueno" (ii).

31 H. A. AcCiarri. El Análisis Económico del Derecho de Daños. Una aproximación general. En: C. BERnAl PUlido y J. FABRA ZAMORA. La filosofía de la Responsabilidad Civil. Estudios sobre los fundamentos filosófico-jurídicos de la responsabilidad civil extracontractual. Bogotá, Universidad Externado de Colombia, 2013, 444. 
Así, i) el empresario "malo" gasta más en pago de condenas, por ejemplo, crea más provisiones contables o contrata más seguros; mientras que ii) el empresario "bueno" gasta más en prevención, por ejemplo, aumenta la calidad de sus productos o mejora las prácticas de manufactura, etc.; sin embargo, cuando estamos en un sistema de responsabilidad objetiva se trata de la misma manera a quien gasta en prevención -empresario "bueno"- y a quien gasta en pago de indemnizaciones y sanciones -empresario "malo"-, lo cual, por un simple razonamiento lógico, incentiva que en el mediano y el largo plazo todos terminen siendo empresarios "malos", porque, como ya lo anotamos, pagar sanciones e invertir en prevenirlas es costoso, de donde solo se podrá asumir el costo de una de ellas; y siendo que a la sanción, en un sistema objetivo, no se puede escapar-salvo condiciones especialísimas como el caso fortuito y la fuerza mayor-, siempre se va a preferir aprovisionar el dinero suficiente para pagar las sanciones ${ }^{32}$.

\section{Responsabilidad subjetiva}

Dicho lo anterior, si, por el contrario, adoptamos un sistema de responsabilidad subjetiva existe mayor probabilidad de generar incentivos a tener un mayor número de empresarios "buenos"; veamos lo siguiente:

... en el ámbito jurídico de los países de herencia romanista la caracterización de la culpa no se vincula explícitamente a consideraciones de costos, sino a estándares representados por modelos ideales ("buen padre de familia", "buen comerciante") o por referencia a conjuntos de prácticas sociales ("las diligencias que exigiere la naturaleza de la obligación correspondiente a las circunstancias de las personas, tiempo y lugar"). En ambos casos, pese a sus diversidades, subsiste la idea de mínimos exigibles. A partir de ese umbral mínimo de precauciones debidas, el individuo que las cumpla no será culpable, sin que importe de allí en más cuánta diligencia asuma en exceso por sobre ese mínimo. Y si la responsabilidad -en un cierto género de casos-requiere su culpabilidad, en ausencia de culpa determinará la correlativa carencia de responsabilidad ${ }^{33}$.

Así, volviendo a lo señalado en cuanto a la responsabilidad objetiva, hay que tener en cuenta que el empresario hace el siguiente análisis: "si la probabilidad del pago de indemnizaciones más sanciones disminuye, se reduce el gasto por

32 E. J. ArChila PeÑalosa. La responsabilidad objetiva y la facultad sancionatoria de la SIC. Contexto, Universidad Externado de Colombia, 2011, n. ${ }^{\circ}$ 35, pp. 3-4.

33 ACCIARRI. El Análisis Económico del Derecho de Daños. Una aproximación general», cit., pp. 444-445. 
pago de indemnizaciones más sanciones, pero a la vez se crean incentivos para reducir el gasto en prevención" ${ }^{34}$.

De acuerdo a lo anterior, tanto en sistemas de responsabilidad subjetiva como objetiva, los dañadores elegirán siempre el nivel óptimo de precaución, que es lo mismo que decir que "el sistema conduce a resultados eficientes" ${ }^{35}$. Pero, en tratándose de consumo, es importante, como ya lo habíamos anotado, centrarse en reducir la asimetría de información, porque solo cuando hay neutralidad respecto del riesgo y los consumidores poseen información perfecta -o por lo menos se acercan a ella- respecto de las empresas y sus productos, podríamos decir que cualquier sistema de responsabilidad (objetivo o subjetivo) sería eficiente ${ }^{36}$, lo cual es algo difícil de alcanzar porque el supuesto de colocación perfecta de la información no es real.

Sin embargo, a lo anterior debemos hacer una aclaración, y es que es mayor la asimetría de información que existe entre la empresa y el consumidor, que la existente entre la empresa y la administración, pues esta última, en primer lugar, está más informada respecto de la actividad que desarrollan las empresas y, en segundo lugar, tiene poder sobre las mismas; de ahí la importancia de la función administrativa sancionadora -más que la jurisdiccional- para lograr cumplir el objetivo de la ley, lo que en últimas podríamos llamar eficiencia dinámica de la autoridad en la aplicación de la ley.

\section{Daños punitivos}

Para seguir sosteniendo nuestra tesis en relación con la innecesaria aplicación de regímenes sancionatorios diferentes al que corresponde por ley (competencia), con la idea de poder imponer sanciones más altas que las que permite el régimen legal correspondiente (consumo), debemos decir que existen mecanismos que ayudan, aun cuando el monto sancionatorio sea "pequeño", a cumplir con la función general preventiva a la que ya hemos hecho alusión, generando el mismo efecto que puede producir echar mano de un régimen diferente dadas las "bondades" de su sanción.

De lo que hablamos en síntesis es de los daños punitivos; el daño punitivo

... [es] un daño en una escala aumentada que se asigna al demandante por encima de lo que simplemente lo compensaría por una pérdida de propiedad, cuando

34 ArChila PeÑalosa. La responsabilidad objetiva y la facultad sancionatoria de la SIC, cit., pp. 3-4.

35 ACCIARRI. El Análisis Económico del Derecho de Daños. Una aproximación general, cit., p. 446.

36 A. Polinsky. Introducción al Análisis Económico del Derecho. Barcelona, Ariel, 1985, p. 115 . 
el daño a él inferido ha sido agravado por circunstancias de violencia o presión, malicia, fraude, o una conducta errada o de extremo atrevimiento y maldad por parte del demandado, y que tiene por objeto calmar o confortar al demandante por su angustia mental, sus sentimientos heridos, su vergüenza, degradación u otras agravaciones del daño original, o castigar al demandado por su mala conducta o hacer de él un ejemplo, razón por la cual se llaman "punitivos" o "vindicativos"37.

Respecto de lo anterior es necesario hacer una anotación, y es que en los sistemas jurídicos del derecho continental, como el colombiano, teóricamente hablando no existe aplicación de este tipo de daños - punitivos-, lo cual implica que la necesaria justificación, que es en últimas el problema de su aplicación, dependerá de quién es el encargado de aplicar la norma, lo que no obsta para su implementación en esta materia -consumo- o al menos para inspirar su filosofía hacia los daños compensatorios; sobre los cuales podemos decir que en materia de sanciones administrativas se tiene la puerta abierta para su aplicación, o por lo menos de lo que se entiende de ella; dado que,

... si la política pública que justifica el daño punitivo en el sistema anglosajón es la de regular conductas mediante las sanciones económicas, en nuestro sistema son muchos los mecanismos que para tal efecto se tienen, verbigracia, las sanciones administrativas que puede imponer el Estado a las personas naturales o jurídicas. Dicha sanción, que buscaría el mismo objetivo que el daño punitivo, sería a favor de quien sufre el daño, es decir, de la sociedad en su conjunto, sin que implique el enriquecimiento de una persona a nombre de aquella ${ }^{38}$.

Tenemos así que "[se otorgan] daños punitivos, [bajo la denominación que se quiera dar], cuando el comportamiento del demandado [la empresa] es malicioso, opresivo, grosero, caprichoso, fraudulento" 39 ; es decir, deberían aplicarse solamente para castigar los comportamientos "maliciosos" -castigar al empresario "malo"-.

\section{El porqué de los daños punitivos}

La Regla de Hand: en un sistema de responsabilidad subjetiva, si el costo en precaución (B) es menor que el valor del daño (L) multiplicado por la probabilidad de ocurrencia del hecho (P), la empresa se supone negligente y debe pagar; es decir:

37 Henao. El daño. Análisis comparativo de la responsabilidad extracontractual del Estado en derecho colombiano y francés, cit., pp. 45-46.

38 Ibíd., p. 48.

39 R. Cooter y T. Ulen. Law \& Economics. Boston, Pearson Addison Wesley, 2004, p. 372 . 
Hay culpa si (B) es menor que (PL) = debería pagarse el daño

No hay culpa si $(B)$ es mayor o igual a $(\mathrm{PL})=$ no debería pagarse el daño

El óptimo social se da en el punto en el cual $(B)=(P L)$

Sin embargo, en general (L) no es pagado plenamente, toda vez que -p. ej.no todas la víctimas demandan -"el error de ejecución"-, luego, en general (PL) tiende a ser artificialmente bajo, lo cual implica una pérdida de eficiencia que debería recuperarse.

En conclusión, en un sistema de responsabilidad subjetiva, la función que cumplen los daños punitivos es recuperar la ineficiencia creada por el menor valor pagado por $(\mathrm{L})$, haciendo que en todo caso la empresa pague $(\mathrm{L})$ como si no hubiese "error de ejecución", lo que incentiva inversiones óptimas -empresario bueno- en (B) hasta que se iguale a (PL), lo que denota eficiencia ${ }^{40}$ en el cumplimiento de la ley, dado que a largo plazo, por cuenta de una mayor inversión en sus productos, habría una tendencia a disminuir el monto de reclamaciones y en consecuencia el número de sanciones.

\section{APLICACIÓN PRÁCTICA A UN CASO EN CONCRETO -ANÁLISIS \\ DE LA RESOLUCIÓN 53403 DE 2013 DE LA SUPERINTENDENCIA \\ DE INDUSTRIA Y COMERCIO-}

Solo como ejercicio académico vamos a repasar unos aspectos puntuales de la Resolución 53403 de 2013, mediante la cual se le impuso una sanción a un operador de telecomunicaciones en Colombia por supuestamente vulnerar la libre competencia, en lo que consideramos fue una violación de los derechos de los usuarios de las TIC's contenido en la Ley 1341 de 2009 y demás normas que la complementan o adicionan.

\section{Presentación del caso ${ }^{41}$}

“A través de la resolución n. ${ }^{\circ} 53403$ de 2013, confirmada mediante la resolución n. . 66934 de 2013, la Superintendencia de Industria y Comercio sancionó a COMCEL (Claro) por infringir lo dispuesto

40 Si bien la Regla de Hand es usada, y de hecho así nació, para explicar los niveles óptimos de precaución en los casos de negligencia, tal y como ocurrió en el caso United States v. Carrol Towing, para este caso lo que hacemos es introducir una variable adicional al valor de daño L (el cual serían los daños punitivos) con el fin de intentar recuperar la ineficiencia creada por el menor valor del daño L (sanción) establecido en la ley de consumo, que es mucho menor que el creado en la ley de competencia pero que serviría como fórmula para igualar los efectos generados por montos sancionatorios diferentes.

41 Tomado del archivo de noticias de la página web de la Superintendencia de Industria y Comercio, consultado el 9 de febrero de 2015: http://www.sic.gov.co/drupal/noticias/node/6534 


\begin{abstract}
en el numeral $6 .^{\circ}$ del artículo 50 del Decreto 2153 de 1992, abusando de su posición dominante en el mercado de Voz Saliente Móvil con el fin de obstruir el acceso de terceros a canales de comercialización. Lo anterior, luego de encontrar probado que a través de conductas relacionadas con el bloqueo de las bandas de equipos móviles celulares, impedía o restringía a los usuarios migrar a otros operadores móviles.
\end{abstract}

\begin{abstract}
"Manipulación o abultamiento de cifras de portabilidad. La Superintendencia también encontró probado que COMCEL S.A. (Claro) infringió lo dispuesto en el artículo 1 de la Ley 155 de 1959, al incurrir en conductas tendientes a limitar la libre competencia, a través del abultamiento (manipulación) de cifras sobre los resultados de la Portabilidad Numérica Móvil (PNM). Sobre este particular, la SIC encontró que COMCEL S.A. (Claro), dentro de una política empresarial, propició condiciones para que se hicieran efectivas portaciones aparentes de líneas hacia su red, que condujeron al reporte de cifras artificiales a las autoridades y al mercado, con las que se pretendió mostrar a COMCEL S.A. (Claro) como el operador preferido por los usuarios en los procesos de Portabilidad Numérica Móvil (PNM)”.
\end{abstract}

La Ley 1341 de 2009, es la ley por medio de la cual "se definen principios y conceptos sobre la sociedad de la información y la organización de las Tecnologías de la Información y las Comunicaciones -TIC-, se crea la Agencia Nacional de Espectro y se dictan otras disposiciones", donde, en su contenido, se establece como principio orientador de la regulación del sector de telecomunicaciones la protección de los derechos de los usuarios de las TIC's, derechos que, por facultad expresa otorgada en la misma ley, le corresponde a la Comisión de Regulación de Comunicaciones -CRC- regular para hacer efectiva su garantía y promoción.

De ahí que la CRC haya expedido la Resolución 3066 de 2011, donde se establece el "Régimen Integral de Protección de los Derechos de los Usuarios de los Servicios de Comunicaciones", que integra junto a la Ley 1341 de 2009 el régimen especial de los derechos de los usuarios en el sector de las TIC's en Colombia.

Sin embargo, la primera conducta por la cual sanciona la Superintendencia de Industria y Comercio -SIC- en ejercicio de su función de garante de la promoción de la competencia es por la llamada "portabilidad numérica", la cual es una violación propia de los derechos de los usuarios de las TIC's -y por lo tanto hace parte de la protección al consumidor-, de acuerdo a lo establecido en la Ley 1245 de 2008 y en el artículo 9. . de la Resolución 3066 de 2011 de la CRC; contrario a lo señalado por la SIC que consideró que se hallaba ante una violación de los artículos $1 .^{\circ}$ de la Ley 155 de 1959 y 50 del Decreto 2153 de 1992.

La segunda conducta que encuentra la SIC en la mencionada resolución de sanción hace referencia a la "apertura de bandas de los equipos y la entrega del número de confirmación", los cuales son aspectos necesarios para una efectiva portabilidad de un proveedor de comunicaciones a otro, portabilidad prevista en los derechos de los usuarios de los servicios de telecomunicacio- 
nes y contenida en los artículos 10 y 105 de la Resolución 3066 de 2011. Sin embargo, para la administración es una clara obstrucción a los canales de comercialización para terceros, enmarcada en el artículo $1 .^{\circ}$ de la Ley 155 de 1959 y el numeral 6 del artículo 50 del Decreto 2153 de 1992, olvidando así la normativa especial aplicable al caso concreto, a saber, la Resolución 3066 de 2011, lo cual suponía una aplicación preferente de las normas de consumo por encima de las de competencia.

Continuando con lo resuelto en la Resolución 53403 de 2013 -sobre la sanción- solo hay un punto que admite debate, por ser de aplicación cruzada, y es el relacionado con la infracción de las normas de publicidad contenidas en el Estatuto de Protección al Consumidor. Lo anterior, en tanto y en cuanto el Decreto 2153 de 1992 en el numeral 1 del artículo 48 lo considera también un acto contrario a la libre competencia ${ }^{42}$; sin embargo, para sancionar por esta modalidad, la conducta debe tener la potencialidad de excluir competidores o impedir el acceso de estos al mercado. A partir de ahí no podemos considerar otras situaciones, como las señaladas anteriormente, como violación al régimen de protección de la competencia, dada su doble caracterización, que incumple además la prohibición del non bis in idem, proscrito para este tipo de procedimientos sancionatorios.

\section{Del abuso de posición de dominio}

Hay un aspecto que llama la atención de la Resolución 53403 de 2013, expedida por la SIC, relacionado con el abuso de posición de dominio, en el entendido de que, para el fallador, la misma ya había sido determinada por el regulador -la CRC- en el año 2011, olvidando que, siempre que exista un presunto abuso de posición de dominio, lo primero que hay que hacer es definir el mercado revelante -tanto geográfico como de producto- y determinar en cuál de ellos existe la posición de dominio; de lo contrario la conducta ya no quedaría inmersa en lo estipulado en el artículo 50 del Decreto 2153 de 1992, sino en el artículo 48 ibíd. Debemos señalar que la definición de mercado relevante que hizo la CRC tuvo un objetivo diferente, esto es, determinar, al momento de hacer la regulación, si exisitía una posición de dominio que hiciera necesaria la imposición de obligaciones para la empresa que se encontrara en esa situación, con el fin de fomentar la competencia; pero una

42 Recordemos que los actos restrictivos son "comportamientos unilaterales dirigidos a todos los comerciantes. Se diferencian de la posición de dominio en la medida en que para los actos restrictivos no se requiere un sujeto calificado específico, sino que agrupan prohibiciones dirigidas a todo el universo de comerciantes": M. Velandia. Derecho de la Competencia y del Consumo. Bogotá, Universidad Externado de Colombia, 2011, p. 195. 
cosa es declarar la posición de dominio para regular el mercado y garantizar condiciones competitivas para todos, y otra muy diferente señalar que hay un abuso de posición de dominio - porque la posición ya fue declarada con otro objetivo diferente- y con ello obtuvo la ventaja competitiva en detrimento de los demás competidores.

Hay que aclarar que cuando existen indicios acerca de la ocurrencia de una posible práctica de abuso de posición de dominio, lo primero que se debe hacer es definir cuál es el mercado de referencia en el que se está llevando a cabo la posible práctica anticompetitiva, el cual está compuesto por dos elementos esenciales: i) el mercado de producto de referencia y ii) el mercado geográfico de referencia.

Tenemos entonces que "el mercado de producto de referencia comprende la totalidad de los productos y servicios que los consumidores consideren intercambiables o sustituibles en razón de sus características, precio o el uso que se prevea hacer de ellos"43.

Por otro lado, el mercado geográfico de referencia "comprende la zona en la que las empresas afectadas desarrollan actividades de suministro de los productos y de prestación de los servicios de referencia, en la que las condiciones de competencia son suficientemente homogéneas y que puede distinguirse de otras zonas geográficas próximas debido, en particular, a que las condiciones de competencia en ella prevalecientes son sensiblemente distintas a aquella" ${ }^{44}$.

Cuando nos centramos en el mercado de las telecomunicaciones debemos aclarar que el mismo es demasiado amplio, es decir, hay muchos pequeños mercados dentro de ese gran mercado, por lo cual se hace necesario fraccionarlo; "esto implica hacer una lista completa de todos los productos que se pueden tener en cuenta en este mercado", teniendo como los criterios más utilizados para separar las comunicaciones electrónicas los siguientes ${ }^{45}$ : i) servicios mayoristas/minoristas; ii) servicio de acceso/tráfico; iii) tipo de red de acceso; iv) información transportada por el servicio, y v) tipo de cliente final.

Así, el ejercicio que debe hacer el fallador no es para nada irrisorio y no consiste en una simple remisión a una resolución -que por lo demás ya estaba devaluada, era del año 2011-, dado que los mercados cambian, se transforman, entre otras razones porque las preferencias de los consumidores son transitivas; además, la presencia de nuevos competidores, que al momento

43 Comunicación de la Comisión relativa a la definición de mercado de referencia a efectos de la normativa comunitaria en materia de competencia. 97/C-372/03.

44 Ibíd.

45 F. Herrera GonzÁlez. La Aplicación de Principios de Derecho de Competencia a la Regulación Sectorial de Telecomunicaciones. Información Comercial Española, ICE: Revista de Economía, 2006, n. ${ }^{\circ} 832$, p. 50. 
de hacer el análisis por parte del regulador no existían, pueden distorisionar completamente la posición de uno o varios competidores en el mercado; de ahí que era necesario hacer un análisis completo por parte de la autoridad de competencia y determinar cuál era el mercado en donde existía posición de dominio, para, paso seguido, estudiar el posible abuso de la misma.

\section{CONCLUSIONES}

De todo lo dicho hasta este punto hay que resaltar varios aspectos sobre los cuales debe quedar absoluta claridad para un mayor entendimiento de lo pretendido en el presente artículo.

En primer lugar -y considero yo que es la conclusión menos discutibledebemos decir que cada norma, que así lo haya contemplado, contiene un régimen de infracciones $\mathrm{y}$, por ende, un régimen de sanciones correspondiente a dichas infracciones; de ahí que utilizar, en un procedimiento administrativo sancionador, las características de un régimen pero con las consecuencias de otro, deja servida la eventual declaratoria de nulidad en un proceso contencioso administrativo. Lo anterior por múltiples razones, de las cuales señalemos dos: i) la violación al principio de legalidad y ii) una funesta suplantación de funciones propias del legislador -recordemos que en Colombia el único que puede expedir una ley es el Congreso de la República-.

En segundo lugar, que además se deriva del primero, debemos decir que, por ejemplo, una resolución como la analizada en el último epígrafe de este artículo, aparte de no respetar el principio de legalidad, tampoco respeta la garantía del non bis in idem - pilar fundamental de los procesos administrativos sancionadores-, toda vez que deja abierta la puerta para que una empresa pueda ser sancionada dos veces por el mismo hecho -la misma infracciónsolo que protegiendo intereses jurídicos diferentes, con lo que se escapa a la posibilidad de que el afectado pueda alegar la cosa juzgada por una indebida aplicación del régimen correspondiente: la primera fue por competencia y nada dice que entonces no lo pueda hacer por consumo (hay que tener en cuenta que la misma resolución ordena compulsar copias a la Delegatura para la Protección del Consumidor de la SIC para lo de su competencia).

Como tercera conclusión importante del presente estudio, debemos decir que el objetivo de cualquier cuerpo normativo no es sancionar, por el contrario, cuando se logra que una ley se cumpla sin necesidad de acudir al reproche se tiene que dicha ley es eficiente; así, traslando ese supuesto al asunto que nos ocupa en estas líneas, debemos decir dos cosas:

i) Que uno de los objetivos que debe cumplir toda norma sancionatoria, pero en este caso hablando de consumo y competencia, es la prevención 
general positiva, con lo cual tenemos que no es necesario usar la segunda -competencia- para lograr dicho efecto en la primera -consumo-, dado su alto monto sancionatorio. Por el contrario, lo que se precisa es, al momento de aplicar la ley, cercionarse de que el modelo de responsabilidad empleado sea aquel que permita incentivar el surgimiento de más empresarios "buenos", los cuales son aquellos que prefieren invertir más en prevenir que en pagar la sanción -este tipo de empresario es el que tiene la posibilidad, en un proceso, de "salvarse" de pagar de acuerdo al grado de culpa incurrido-.

ii) También debemos decir que con la implementación de un sistema de daños "punitivos" -o al menos en filosofía similar- que cumple la función específica de recuperar la inficiencia creada por el menor valor pagado por el daño, haciendo que en todo caso la empresa pague los daños ocasionados como si no hubiese "error de ejecución", se incentivan inversiones óptimas en precaución, al menos hasta igualar el valor del daño multiplicado por la probabilidad de ocurrencia del hecho, lo cual denotaría eficiencia en el cumplimiento de la ley, dado que, por cuenta de una mayor inversión en sus productos, habría una tendencia a disminuir el monto de reclamaciones y en consecuencia el número de sanciones.

Por último, hay que señalar que la posición de dominio se prueba, y que no es posible utilizar como tal la medición hecha con anterioridad por el regulador, dado que los fines son diferentes. La declaratoria de posición de dominio que hace el regulador tiene la finalidad de imponer obligaciones específicas para mantener equilibradas las cargas del mercado y propiciar la competencia -regulación ex ante-, mientras que la declaratoria de posición de dominio que hace la autoridad de competencia - ex post- tiene por objeto probar que se abusó de ella en un mercado determinado, el cual puede ser diferente al mercado donde el regulador declaró dicha posición -no olvidemos que los mercados pueden a su vez tener sub mercados, y ello no implica que la posición de dominio esté en todos: puede estar solo en uno-.

\section{BIBLIOGRAFÍA}

ACCIARRI, H. A. El Análisis Económico del Derecho de Daños. Una aproximación general. En: C. Bernal Pulido; J. Fabra Zamora, La filosofía de la Responsabilidad Civil. Estudios sobre los fundamentos filosófico-jurídicos de la responsabilidad civil extracontractual. Bogotá, Universidad Externado de Colombia, 2013.

AMADOR CABRA, L. E. Regulación, fallas del mercado y eficiencia económica en el sector del saneamiento básico. En: C. Blanco BArón, A. Guerra Barón, M. A. Pinzón CAMARgo, A. Palacios Lleras y L. E. Amador Cabra. Coleción Enrique Low Murtra Derecho Económico VII. Bogotá, Universidad Externado de Colombia, 2010. 
Archila Peñalosa, E. J. La responsabilidad objetiva y la facultad sancionatoria de la SIC. Contexto, n. $^{\circ}$ 35, Universidad Externado de Colombia, 2011, 3-4.

Ariño Ortiz, G. Principios de Derecho Público Económico. Bogotá, Universidad Externado de Colombia, 2003.

BARCia Lehmann, R. Los efectos de las obligaciones desde la perspectiva del Análisis Económico del Derecho. Cuadernos de Análisis Jurídicos. Colección de Derecho Privado I. Temas de Responsabilidad Civil. Universidad Diego Portales, Escuela de Derecho, 2004, 127-169.

Cooter, R. y T. Ulen. Law \& Economics. Boston, Pearson Addison Wesley, 2004.

Correa Henao, M. Libertad de empresa en el Estado Social de Derecho. Bogotá, Universidad Externado de Colombia, 2008.

GÓMEZ POMAR, F. La relación entre normativa sobre protección de consumidores y normativa sobre defensa de la competencia. Barcelona, Working Paper n. ${ }^{\circ}$ 113, 2003.

Henao, J. C. El daño. Análisis comparativo de la responsabilidad extracontractual del Estado en derecho colombiano y francés. Bogotá, Universidad Externado de Colombia, 1998.

Herrera GonZÁlez, F. La aplicación de principios de derecho de competencia a la regulación sectorial de telecomunicaciones. Información Comercial Española, ICE: Revista de Economía, 2006, n. ${ }^{\circ} 832,45-57$.

MIRANDA LONDOÑO, A. Origen y evolución del Derecho de la Competencia en Colombia. La Ley 155 de 1959 y su legado. Revista de Derecho de la Competencia, Bogotá, diciembre de 2011, 65-148.

Nieto, A. Derecho Administrativo Sancionador. Madrid, Tecnos, 1994.

Ossa Arbeláez, J. Derecho Administrativo Sancionador. Hacía una teoría general y una aproximación para su autonomía. Bogotá, Legis, 2000.

Ossa Bocanegra, C. Fundamentos de la aplicación pública del derecho de la competencia en Colombia. Revista Facultad de Derecho y Ciencias Políticas, Universidad Pontificia Bolivariana, Medellín, 2014, vol. 44, n. 120.

Parejo Alfonso, L.; A. Jiménez-Blanco y L. Ortega Álvarez. Manual de Derecho Administrativo. Barcelona, Ariel, 1990.

Pérez Luño, A-E. La Tercera Generación de Derechos Humanos. Navarra, Thomson Aranzadi, 2006.

Polinsky, A. Introducción al Análisis Económico del Derecho. Barcelona, Ariel, 1985.

Resico, M. Introducción a la Economía Social de Mercado. Rio de Janeiro, Konrad Adenauer Stiftung, 2011.

Rivero Ortega, R. Derecho Administrativo Económico. Madrid, Marcial Pons, 2009. 
Santamaría Pastor, J. A. Principios de Derecho Administrativo, Madrid, Centro de Estudios Ramón Areces, 1994.

Santofimio Gamboa, J. O. Tratado de Derecho Administrativo, vol. II, Acto administrativo. Bogotá, Universidad Externado de Colombia, 2003.

SARMiento Ramírez-Escudero, D. El principio de proporcionalidad en el Derecho Administrativo. Un análisis jurídico desde el derecho español. Bogotá, Universidad Externado de Colombia, 2007.

SHAVELL, S. Responsabilidad extracontractual por accidentes en el análisis económico del derecho. En: C. Bernal PUlido y J. FABra Zamora. La filosofía de la Responsabilidad Civil. Estudios sobre los fundamentos filosófico-jurídicos de la responsabilidad civil extracontractual. Bogotá, Universidad Externado de Colombia.

Stiglitz, J. E. La economía del sector público. Barcelona, Bosch, 2000.

Uprimny YePes, R. y C. A. RodRíGuez G. Constitución y modelo económico en Colombia: hacia una discusión productiva entre economía y derecho. Centro de Estudios de Derecho, Justicia y Sociedad. Bogotá, 2005, 21.

Velandia, M. Derecho de la Competencia y del Consumo. Bogotá, Universidad Externado de Colombia, 2011.

Comisión Europea. Comunicación relativa a la definición de mercado de referencia a efectos de la normativa comunitaria en materia de competencia. 97/C-372/03.

Constitución Política de Colombia.

Corte Constitucional. Sentencia C-818 de 9 de agosto de 2005, M.P. Rodrigo Escobar Gil, exp. D-5521.

Decreto 2153 de 1992.

Ley 1245 de 2008.

Ley 1340 de 2009.

Ley 1341 de 2009.

Ley 1480 de 2011.

Ley 155 de 1959.

Resolución CRC n. ${ }^{\circ} 3066$ de 2011.

Resolución SIC n. ${ }^{\circ} 53403$ de 2013.

Tribunal Constitucional de España. Sentencia n. ${ }^{\circ} 61$ de 29 de marzo de 1990. 